\title{
Tandem Mass Spectrometry of Poly(Ethylene Glycol) Lithium-Attachment Ions
}

\author{
Robert P. Lattimer \\ The BFGoodrich Research and Development Center, Brecksville, Ohio, USA
}

\begin{abstract}
A study of the fast-atom bombardment tandem mass spectrometry behavior of a number of ethylene glycol polymers (PEGs) has been carried out. Both linear (hydroxyl, amino, and/or alkyl end groups) and cyclic (crown ether) polymers were studied. One of the materials is a block copolymer of ethylene and propylene oxides. Collisional activation was carried out in the collision octapole of a BEOQ hybrid mass spectrometer at a translational energy of $50 \mathrm{eV}$, with collision gas air. For the linear polymers, the most intense product ions are lithiated, linear polyglycol oligomers. These ions are formed via internal hydrogen transfer reactions that are facilitated (charge-induced) by lithium. This series of product ions allows for the observation of consecutive losses of monomer units from the chain end; this is useful to determine the sequence of monomers in a copolymer. The most abundant product ions from cyclic PEGs are lithiated radical cations. An especially interesting finding in this work is the preferential loss of two internal ethylene oxide (EO) units (dioxane, $88 \mathrm{u}$ ) from some $[\mathrm{M}+\mathrm{Li}]^{-}$precursors. Factors that influence this loss include (a) the sequence length of $\mathrm{EO}$ repeat units in the oligomer and (b) the identity of the end group(s) on the oligomer. It is proposed that this elimination of dioxane involves a six-membered ring intermediate; this decomposition reaction is believed to be a lithium-mediated (charge-induced) rearrangement. (J Am Soc Mass Spectrom 1994, 5, 1072-1080)
\end{abstract}

$\mathrm{N}$ umerous applications of tandem mass spectrometry in polymer science have been described in recent years. Three specific areas have been considered: (1) identification of organic additives in compounded polymers, (2) identification of volatile pyrolyzates in polymer pyrolysis studies, and (3) characterization of individual oligomers in low molecular weight polymers. This report focuses on the tandem mass spectrometry behavior of the poly(ethylene glycol) (PEG) class of low molecular weight polymers. A large number of PEGs have been studied by mass spectrometry via various desorption-ionization methods. Several reports have included some description of polyglycol tandem mass spectrometry behavior. Ionization methods employed include field desorption [1 3], chemical ionization [4-6], and fast atom bombardment [7-11]. Many of these studies reported sequential losses of ethylene oxide (EO) units from the precursor ions.

Earlier work from our laboratory investigated the tandem mass spectrometry behavior of $\left[\mathrm{M}+\mathrm{H}^{+}\right.$, $[\mathrm{M}+\mathrm{Na}]^{+}$, and $\left[\mathrm{M}+\mathrm{Li}^{+}\right.$ions frum linear and cyclic ethylene and propylene glycol polymers [9-11]. The $[\mathrm{M}+\mathrm{H}]^{+}$ions fragmented readily under low energy collisional activation $(\approx 50 \mathrm{eV})$, and the principal product ions formed were due to charge-induced de-

Address reprint requests to Robert $P$. Tattimer, Research and Development Center, The BFGoodrich Company, 9921 Brecksville Road, Brecksville, Ohio 44141. compositions and consecutive losses of ethylene oxide or propylene oxide units $[9,11]$. The $[\mathrm{M}+\mathrm{Na}]^{+}$ions were found to be very stable toward cleavage of $\mathrm{C}-\mathrm{O}$ and $\mathrm{C}-\mathrm{C}$ bonds; only very weak sodiated organic product ions were formed $[9,10] .[\mathrm{M}+\mathrm{Li}]^{+}$ions, on the other hand, were found to dissociate to lithiated organic fragments with reasonable efficiency; four series of product ions were characterized [10].

This report presents results from investigation of $\left[\mathrm{M}+\mathrm{Li}^{+}\right.$ions from additional ethylene glycol polymers. Both linear (hydroxyl, amino, and/or alkyl end groups) and cyclic (crown ether) polymers were studied. These results support and extend earlier mechanistic conclusions [10], An especially interesting finding is the preferential loss of two EO units (dioxane, $88 \mathrm{u}$ ) from some $\left[\begin{array}{lll}\mathrm{M} & \mathrm{L} & \mathrm{Li}\end{array}\right]^{+}$precursors.

\section{Experimental}

A Finnigan MAT (Bremen, Germany) $95 \mathrm{Q}$ hybrid mass spectrometer with $\mathrm{BEOQ}$ geometry was used for analysis. Collisional activation was carried out in the "collision octapole" with translational energy ( $\left.E_{\text {lab }}\right)$ of $50 \mathrm{eV}$ and collision gas air. The pressure in the collision cell was adjusted to $\approx 0.2 \mathrm{~Pa}$, which corresponds to a pressure in the quadrupole analyzer region of $\approx 8 \times$ $10^{-4} \mathrm{~Pa}$. For linear PEG under these conditions, the most abundant product ions were $\approx 2-10 \%$ of the $[\mathrm{M}+\mathrm{Li}]^{+}$precursor ion intensity. These conditions 
predominately result in single collisions within the cell.

The tandem mass spectrometry experiments were carried out by using fast-atom bombardment (FAB) ionization. The aluminum FAB target was introduced via the direct probe inlet. Key instrument parameters were as follows: accelerating voltage $5 \mathrm{kV}$, magnetic sector resolution $\approx 800$, and ion source temperature $\approx 30 \mathrm{C}$. The mass-separating quadrupole was generally operated at "unit resolution" by using the $50 \%$ valley definition. Scans for both the magnetic sector and mass-separating quadrupole were controlled by the data system. In typical experiments, profile data were acquired while the quadrupole was scanned at a rate of $100 \mathrm{u} / \mathrm{s}$. About $50-100$ product ion scans were accumulated to obtain a composite spectrum, which was then smoothed with a five-point function.

Two linear PEGs, $\mathrm{CH}_{3} \mathrm{O}+\mathrm{CH}_{2}-\mathrm{CH}_{2}-\mathrm{O}-\rightarrow_{n} \mathrm{R}$, were examined: PEG methyl ether (PEGME; $\mathrm{R}=\mathrm{H}$; $M_{n} \approx 550$; Aldrich Chemical Co., Milwaukce, WI) and PEG dimethyl ether (PEGDME; $\mathrm{R}=\mathrm{CH}_{3} ; M_{n} \approx 430$; Polysciences, Warrington, PA). Two cyclic PEGs also were examined: 18-crown-6 (MW 264; Aldrich) and 15-crown-5 (MW 220; Aldrich). Finally, an amine-terminated polyglycol was studied: $\left.\left.\mathrm{C}_{4} \mathrm{H}_{9}+\mathrm{O}-\mathrm{CH}_{2}-\mathrm{CH}_{2}\right)_{m}+\mathrm{O}-\mathrm{CH}_{2}-\mathrm{CHCH}_{3}\right)_{n}$ $\mathrm{NH}_{2}$. This material is Jeffamine M-360 (Jefferson Chemical Co., Houston, TX); it may be considered to be a block copolymer of ethylene and propylene oxides, where $m=2-10$ and $n=1-4$. The viscous liquid samples were placed directly on the FAB target for analysis. To effect cation attachment, $1 \mu \mathrm{L}$ of a satu- rated solution of $\mathrm{LiBr}$ in methanol was added. $[\mathrm{M}+$ $\mathrm{Li}^{+}$ions readily form from polyglycols under these conditions; the concentration of the added salt is not critical. Deuterated polyglycol samples were prepared by mixing PEGME or M-360 with a large excess of $\mathrm{D}_{2} \mathrm{O}$ (99.8 at \% D; Merck, Sharpe \& Dohme Isotopes, Dorval, Quebec) in a vial. The vial was then evaporated over a stream of dry nitrogen at room temperature. Lithium bromide, when added to the deuterated polyglycols for analysis, was prepared as a solution in $\mathrm{D}_{2} \mathrm{O}$.

\section{Results and Discussion}

\section{PEG Methyl Ether}

Figure 1 is the product ion scan of $m / z 479$ from PEG methyl ether, which is $[\mathrm{M}+\mathrm{Li}]^{+}$for the decamer ${ }^{7} \mathrm{Li}\left[\mathrm{CH}_{3}-\mathrm{O}+\mathrm{CH}_{2}-\mathrm{CH}_{2}+{ }_{10} \mathrm{H}\right]^{+}$. Figure 2 is the product ion scan for the $d_{1}$-decamer: ${ }^{7} \mathrm{Li}\left[\mathrm{CH}_{3}-\mathrm{O}-\left(-\mathrm{CH}_{2}-\mathrm{CH}_{2}-\mathrm{O} \rightarrow{ }_{10} \mathrm{D}\right]^{+}\right.$. Product ions are observed throughout the mass range, and the spectra are quite complex. Essentially all of the product ions are contained in eight series. Four of these contain the intact hydroxyl end group (A, B, C, D) and the other four contain the intact methoxy group ( $A^{\prime}$, $\left.B^{\prime}, C^{\prime}, D^{\prime}\right)$. The formation of these product ions is analogous to that described earlier for dihydroxylterminated PEG [10]. Hence only a brief description will be given here, and mainly the new features (e.g. the unique ion labeled $\mathbf{E}$ ) will be emphasized.

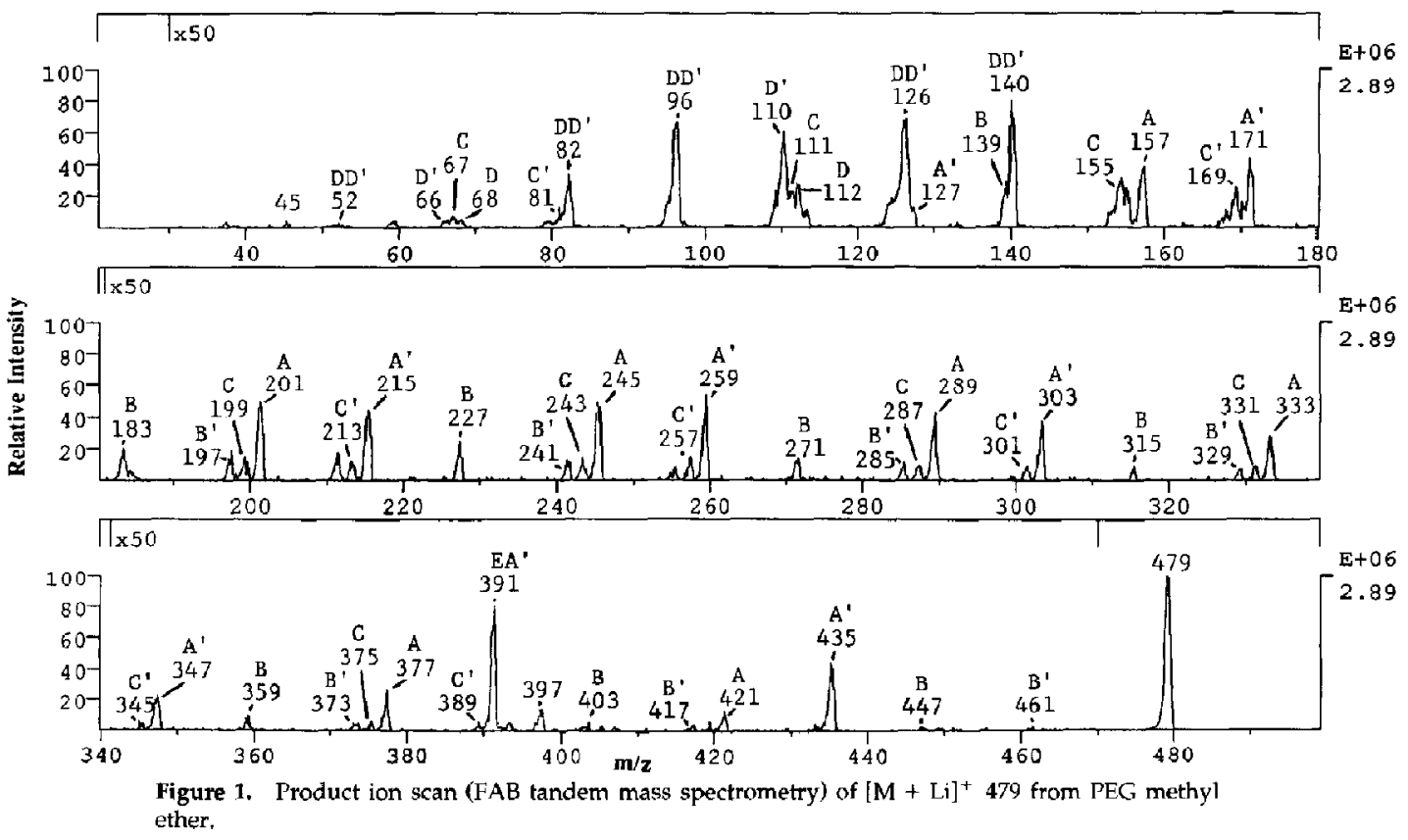


$A$ and $A^{\prime}$ series. These are lithiated, linear oligomers of ethylene glycol:

$$
\begin{array}{r}
\text { A. } \quad \mathrm{Li}\left[\mathrm{HO}+\mathrm{CH}_{2}-\mathrm{CH}_{2}-\mathrm{O}+{ }_{n} \mathrm{H}^{+}\right. \\
\quad m / z 44 n+25 . \\
\text { A'. }^{\prime} \quad \mathrm{Li}\left[\mathrm{CH}_{3}-\mathrm{O}+\mathrm{CH}_{2}-\mathrm{CH}_{2}-\mathrm{O}+{ }_{n} \mathrm{H}\right]^{+} \\
m / z 44 n+39 .
\end{array}
$$

Note that the $\mathbf{A}$ and $\mathbf{A}^{\prime}$ series are the dominant product ions (except for ion $\mathbf{E}$ ) at higher masses. These ions are believed to be formed via charge-induced hydrogen rearrangements as shown in Scheme I [10]. Internal cleavages that occur more than two units from the chain terminus do not seem to be influenced by the end group. That is, if one compares $\mathbf{A}, \mathbf{A}^{\prime}$ pairs separated by $14 \mathrm{u}$ (e.g., $157-171$ and $201-215$ in Figure 1), the intensities are roughly equal. For the deuterated molecule (Figure 2), the A-series ions are predominately singly deuterated, as expected from Scheme I. The $\mathbf{A}^{\prime}$ product ions up to and including the octamer $(m / z$ 391) remain undeuterated, also as expected from Scheme I. The $\mathbf{A}^{\prime}$ nonamer, however, is mostly singly deuterated in the $d_{1}$-PECME spectrum (Figure $2, \mathrm{~m} / \mathrm{z}$ 436). This $d_{1}$ nonamer may be explained by a logical extension of Scheme I to the end ethylene oxide group:

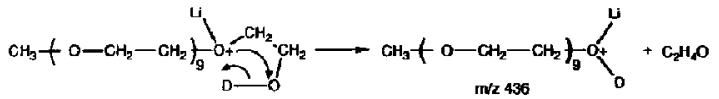

In this case it is clear that only the hydroxyl hydrogen (or deuterium) is readily available for transfer to form the $m / z 436$ product ion.

E product ion. Perhaps the most interesting feature of

$$
\mathrm{H}+\mathrm{O}-\mathrm{CH}_{2}-\mathrm{CH}_{2} \frac{\mathrm{m}_{\mathrm{m}}}{2}{ }_{\mathrm{CH}_{2}} \text { fO- } \mathrm{CH}_{2}-\mathrm{CH}_{2}+\mathrm{OH}_{\mathrm{n}} \text {. }
$$

$$
\left.\mathrm{H}+\mathrm{O}-\mathrm{CH}_{2}-\mathrm{CH}_{2}\right)_{\mathrm{m}} \mathrm{O}_{\mathrm{H}}^{\prime \mathrm{H}}+\mathrm{C}_{2} \mathrm{H}_{4}+\mathrm{OCH}-\mathrm{CH}_{2}+\mathrm{O}-\mathrm{CH}_{2}-\mathrm{CH}_{2} \mathrm{O}_{\mathrm{O}} \mathrm{OA}^{\mathrm{O}}
$$

$A\left(R=H, R^{\prime}=C_{3}\right) m / z 44 m+25$

$A\left\langle R=D, R^{\prime}=C_{3}\right) m / 244 m+26$

$A^{\prime}\left(\mathbf{R}=\mathrm{CH}_{3}, \mathrm{R}^{\prime}=\mathrm{H}\right.$ or $\mathrm{D}$ or $\left.\mathrm{CH}_{3}\right) \mathrm{m} / \mathrm{z} 44 \mathrm{~m}+39$

Scheme I

the PEGME spectra is the intense ion at $m / z 391$ (Figure 1) and $\mathrm{m} / z 392$ (Figure 2). At first glance this ion seems to be a member (octamer) of the $A^{\prime}$ series. This assignment does not seem consistent, however, with the unusual intensity of this ion; that is, it is considerably more abundant than either the heptamer $(m / z 347)$ or nonamer $(m / z 435 / 436)$ in the $\mathbf{A}^{\prime}$ series. This suggests that some unique decomposition reaction is taking place to produce this ion, which will be designated $\mathbf{E}$. It is believed that this reaction is a preferred elimination of two internal ethylene oxide groups (dioxane, $88 \mathrm{u}$ ), as shown in Scheme II. The E ion shifts $1 \mathrm{u}$ higher in mass for the $d_{1}$-PEGME precursor (Figure 2), consistent with Scheme II. This preferred elimination of dioxane was observed earlier in the collisional dissociation of $[\mathrm{M}+\mathrm{H}]^{+}$precursors for

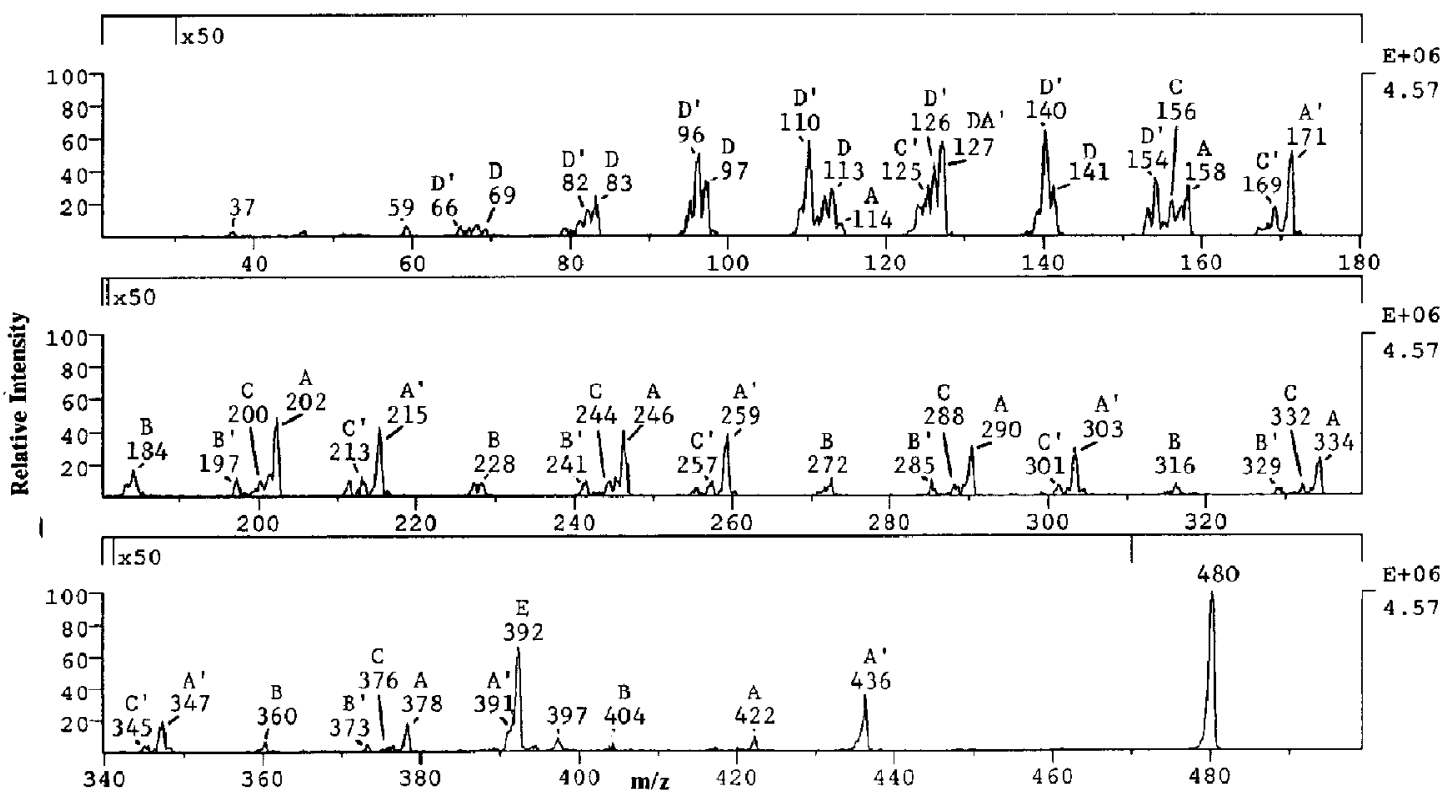

Figure 2. Product ion scan (FAB tandem mass spectrometry) of $\left[\mathrm{M}+\mathrm{Lil}^{+} 480\right.$ from $d_{1}$-PEG methyl ether. 


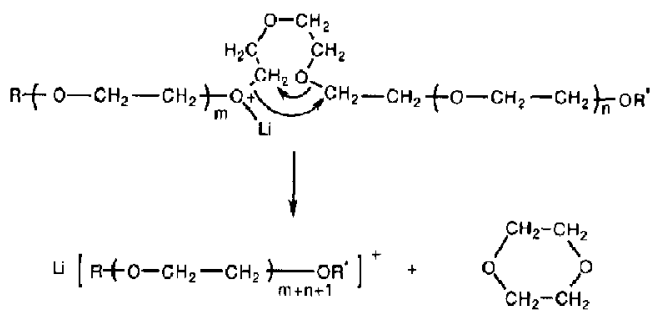

$E\left(R=H_{1} \mathbf{R}^{\prime}=\mathrm{CH}_{3}\right) \mathrm{m} / \mathrm{I} 44(\mathrm{~m}+\mathrm{n}+1)+39$

$E\left(R=D, A^{\prime}=C_{1}\right) m / z 44(m+n+1)+40$

$E\left\{H=A^{\prime}=C H_{3}\right) m / z 44(m+n+1)+53$

Scheme II

both linear (dihydroxyl-terminated) and cyclic (crown ether) PEGs [11]. Recent neutralization-reionization results show dioxane to be present as a neutral product of the dissociation of $[\mathrm{M}+\mathrm{H}]^{+}$ions from crown ethers [12]. Dioxane loss was not a prominent decomposition pathway for $[\mathrm{M}+\mathrm{Li}]^{+}$ions from dihydroxyl-terminated PEG, however [10]. Overall, the internal elimination of dioxane does seem to be a plausible decompusition pathway for PEGs, because the rearrangement can proceed via a six-membered ring intermediate (Scheme II). The high relative intensity of this unique $E$ ion is indicative of a chargeinduced, as opposed to a charge-remote, pathway.

$B / B^{\prime}$ and $C / C^{\prime}$ series. These product ions most likely are formed via charge-remote fragmentations, as shown in Scheme III [10]. These ions are less intense than the $\mathbf{A} / \mathbf{A}^{\prime}$ ions. This is logical because chargeinduced reactions (which form the $\mathbf{A}$ and $\mathbf{A}^{\prime}$ ions) are energetically favored over charge-remote pathways. The $\mathbf{B}$ and $\mathbf{C}$ ions from the $d_{1}$-PEGME precursor (Figure 2) are shifted as expected to mass values 1 u higher than for the $d_{0}$ precursor (Figure 1). The $\mathbf{B}^{\prime}$ and $C^{\prime}$ ions remain undeuterated, also as expected.

$\boldsymbol{D}$ and $\boldsymbol{D}^{\prime}$ series. These are radical cations cantaining lithium [10]; see Scheme IV. The D product ions formed from the $d_{1}$-PEGME precursor are shifted as expected $1 \mathrm{u}$ higher, whereas the $\mathrm{D}^{\prime}$ ions remain unaffected by deuteration. The $\mathrm{D}$ and $\mathrm{D}^{\prime}$ ions are formally distonic, although rearrangements may occur to form other structures.

\section{PEG Dimethyl Ether}

Figure 3 is the product ion scan of $m / z 449$ from PEG dimethyl ether. This is $[\mathrm{M}+\mathrm{Li}]^{+}$for the nonamer: $\mathrm{Li}\left[\mathrm{CH}_{3}-\mathrm{O}+\mathrm{CH}_{2}-\mathrm{CH}_{2}-\mathrm{O} \rightarrow{ }_{9} \mathrm{CH}_{3}\right]^{+}$. This spectrum is considerably less complex than that for PEGME (Figures 1 and 2). The most interesting feature in Figure 3 is the $(\mathrm{M} \cdot \mathrm{Li}-88) \mathbf{E}$ product ion at $m / z 361$. This is the most intense product ion observed, and its

$$
\begin{aligned}
& \left.4\left[\mathrm{H}+\mathrm{O}-\mathrm{CH}_{2}-\mathrm{CH}_{2}\right)_{m} \mathrm{O}-\mathrm{HCH}_{\mathrm{CH}_{2}-\mathrm{O}^{\prime}}^{\mathrm{C} H}-\mathrm{CH}_{2}+\mathrm{O}-\mathrm{CH}_{2}-\mathrm{CH}_{2}+{ }_{\pi} \mathrm{OH}^{\prime}\right]^{+} \\
& -\mathrm{H}_{2} \\
& \left.L\left[\mathrm{r}+\mathrm{O}-\mathrm{CH}_{2}-\mathrm{CH}_{2}\right)_{\mathrm{m}} \mathrm{O}-\mathrm{CH} \mathrm{CH}_{2}\right]^{+}+\mathrm{OCH}_{1}-\mathrm{OH}_{2}+\mathrm{O}-\mathrm{CH}_{2}-\mathrm{CH}_{2} \mathrm{~T}_{\mathrm{n}} \mathrm{Or}^{\prime}
\end{aligned}
$$

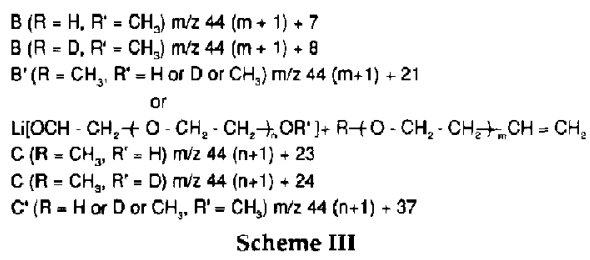

formation via dioxane elimination (Scheme II) seerns straightforward. Note that this ion is completely unique in PEGDME; that is, its mass value does not fall into any of the other extant series. Also note that little, if any, multiple loss of dinxane is evident (e.g., [MH $\left.-2 \times \mathrm{C}_{4} \mathrm{H}_{8} \mathrm{O}_{2}\right]^{+}$would be $m / z 273$ in Figure 3 ). This likely is due to the fact that the relatively mild conditions in the collision cell preclude multiple dissociations. Essentially all of the other product ions in Figure 3 are contained in four series $\left(\mathbf{A}^{\prime}, \mathbf{B}^{\prime}, \mathbf{C}^{\prime}, \mathbf{D}^{\prime}\right)$. The formation of these ions is analogous to their formation from PEGME, as discussed in the preceding section.

\section{8-Crown-6 and 15-Crown-5}

Figure 4 is the product ion scan of $\left[\mathrm{M}+\mathrm{Li}^{+} 271\right.$ from the cyclic ethylene oxide hexamer (18-crown-6). This spectrum is dominated by D-series radical cations. These may be formed in a two-step process: the first step is an opening of the ring with a concerted hydrogen transfer:

$$
\left.M \longrightarrow \mathrm{CH}_{2}-\mathrm{O}_{+}^{\mathrm{L}}-\mathrm{CH}_{2}-M \longrightarrow \mathrm{CH}_{2}=\mathrm{CH}+\mathrm{O}-\mathrm{CH}_{2}-\mathrm{CH}_{2}\right)_{\mathrm{n}} \sum_{\mathrm{L}}^{\mathrm{H}}
$$

This open-rhain intermediate may then undergo homolytic cleavage to form $D$-series product ions (Scheme IV). Other ion serics (A, B, C) are present in the 18-crown-6 product ion scan, but these are quite weak. It is probably not useful to speculate on their detailed chemical structures or mechanisms of formation. Somewhat surprising in Figure 4 is the lack of an intense $(\mathrm{M} \cdot \mathrm{Li}-88) \mathrm{E}$ ion $(m / z 183)$. Based on the results for PEGME and PEGDME, one might expect this ion to be more prominent. The ring conformation necessary for dioxane elimination must not be readily achievable with the crown ether $\left[\mathrm{M}+\mathrm{Li}^{+}\right.$cation. Perhaps the reaction intermediate contains too much strain when only six ethylene oxide units are present in the molecule. It seems probable that crown ethers that contain larger numbers of ethylene oxide units would be more inclined to eliminate dioxane. 


$$
\begin{array}{llllllll}
D^{\prime}\left(\mathrm{R}=\mathrm{CH}_{3}\right) & 66 & 82 & 96 & 110 & 126 & 140 & 154 \\
D(\mathrm{R}=\mathrm{D}) & 53 & 69 & 83 & 97 & 113 & 127 & 141 \\
\mathrm{D}(\mathrm{R}=\mathrm{H}) & 52 & 68 & 82 & 96 & 112 & 126 & 140 \\
+\mathrm{L}\left[\mathrm{RO}-\mathrm{CH}_{2}-\mathrm{CH}_{2}-\mathrm{O}-\mathrm{CH}_{2}-\mathrm{CH}_{2}-\mathrm{O}-\mathrm{CH}_{2}-\mathrm{CH}_{2}-\mathrm{O}-\right. \\
\text { Scheme IV }
\end{array}
$$

The $\left[\mathrm{M}+\mathrm{Li}^{+} 227\right.$ ion for the cyclic pentamer, 15-crown-5, was also examined. The product ion features were analogous to those for 18-crown-6. That is, the $D$-series product ions were dominant. Interestingly, the most abundant $\mathbf{D}$ ions were $m / z$ 68 and 96 for 15-crown-5, whereas $m / z 82$ and 112 were most abundant for $18-$-crown-6. The $(\mathrm{M} \cdot \mathrm{Li}-88) \mathrm{E}$ ion did not possess unusual intensity for $15-$ crown-5.

\section{Jefformine M-360}

This material was studied as an example of a more complex PEG derivative. The main objective was to assess the capability of tandem mass spectrometry to elucidate the structure of a copolymer with two different end groups. A field desorption (FD) mass spectrum of M-360 is included as Figure 5. FD mass spectrometry is very useful for obtaining an overview or profile of the various oligomers, because essentially all ions observed are due to molecular species, in this case $[\mathrm{M}+\mathrm{H}]^{+}$. The FD mass spectrometry data are consistent with the material being a copolymer of ethylene and propylene oxides, with butyl and amino end groups:

$$
\begin{aligned}
& \mathrm{C}_{4} \mathrm{H}_{9}+\mathrm{O}-\mathrm{CH}_{2}-\mathrm{CH}_{2}+{ }_{m} \\
& +\mathrm{O}-\mathrm{CH}_{2}-\mathrm{CHCH}_{3}+{ }_{n} \mathrm{NH}_{2} \\
& \quad M W=44 m+58 n+73
\end{aligned}
$$

The observed oligomers are in the range $n=2-10$ and $n=1-4$. The $m$ and $n$ values for each oligomer are noted in parentheses in Figure 5.

FAB mass spectrometry was used to obtain $[M+$ $\mathrm{Li}^{+}$ions for tandem mass spectrometry. Figure 6 is the product ion scan for the $\left[\mathrm{M}+\mathrm{Li}^{+} 416(m=5\right.$, $n=2$ ) ion and Figure 7 is the product ion scan for $\left[\mathrm{M}+\mathrm{Li}^{+} 418\right.$ from the $d_{2}$ precursor $\left(-\mathrm{ND}_{2}\right)$. Note first of all that product ions are more intense at the higher masses. The $(\mathrm{M} \cdot \mathrm{Li}-88) \mathrm{E}$ ion is quite intense. Its origin is believed to be an internal loss of two ethylene oxide (EO) units (Scheme II). There is no evidence for a similar internal loss of propylene oxide (PO). That is, losses of an EO-PO dimer (MW 102) or a PO-PO dimer (MW 116) are not observed. Thus the preferred loss of dioxane must be quite specific for the $[\mathrm{M}+\mathrm{Li}]^{i}$ ions.

There is only one series of intense product ions, labeled $\mathrm{F}$ in Figures 6 and 7. These ions contain the intact butyl group:

$$
\begin{aligned}
& \left.\mathrm{Li}_{4} \mathrm{H}_{9}+\mathrm{O}-\mathrm{CH}_{2}-\mathrm{CH}_{2}+\right)_{n} \\
& \left.-\left(\mathrm{O}-\mathrm{CH}_{2}-\mathrm{CHCH}_{3}\right)_{n} \mathrm{OH}\right]^{+} \\
& \quad m / z 44 m+58 n+81
\end{aligned}
$$

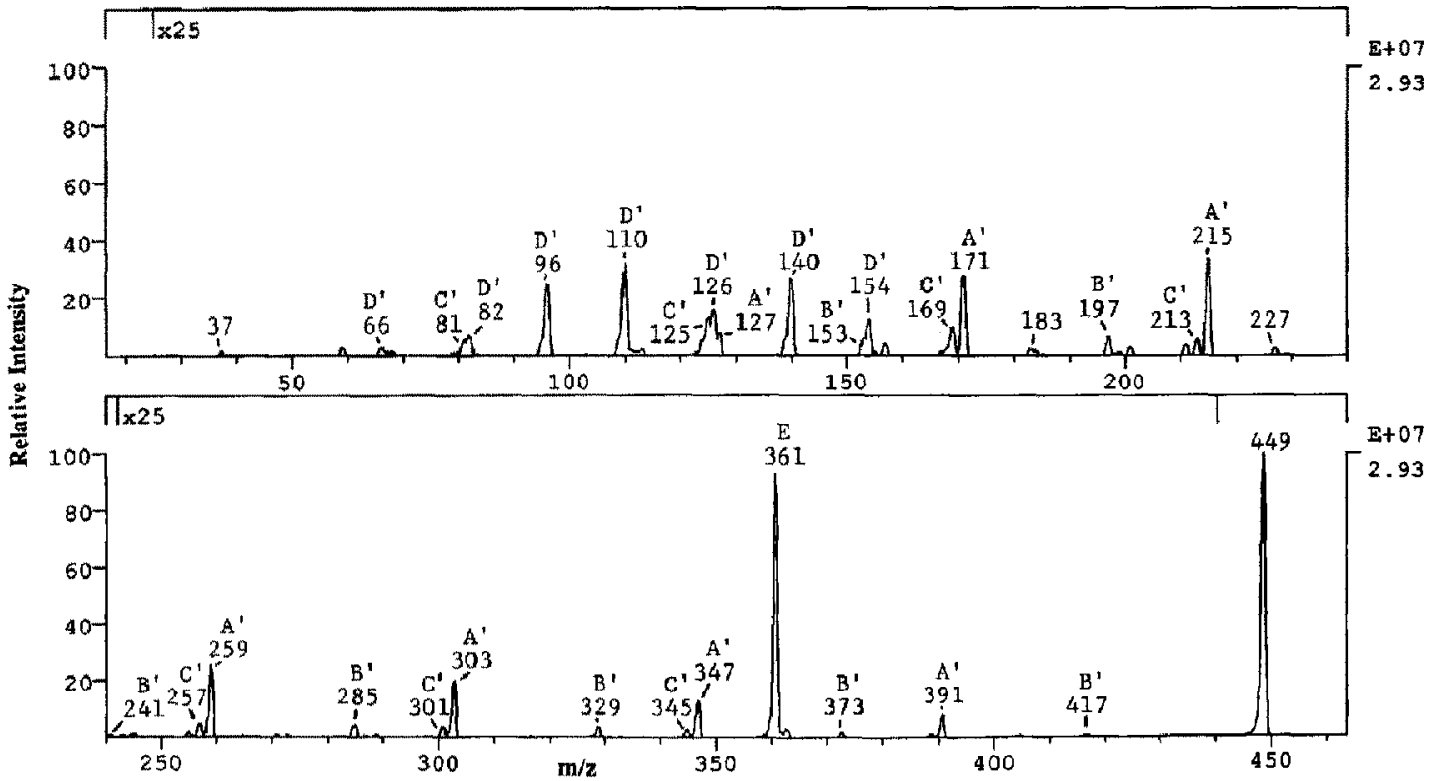

Figure 3. Product ion scan (FAB tandem mass spectrometry) of $\left[\mathrm{M}+\mathrm{Li}^{+} 449\right.$ from PEG dimethyl ether. 


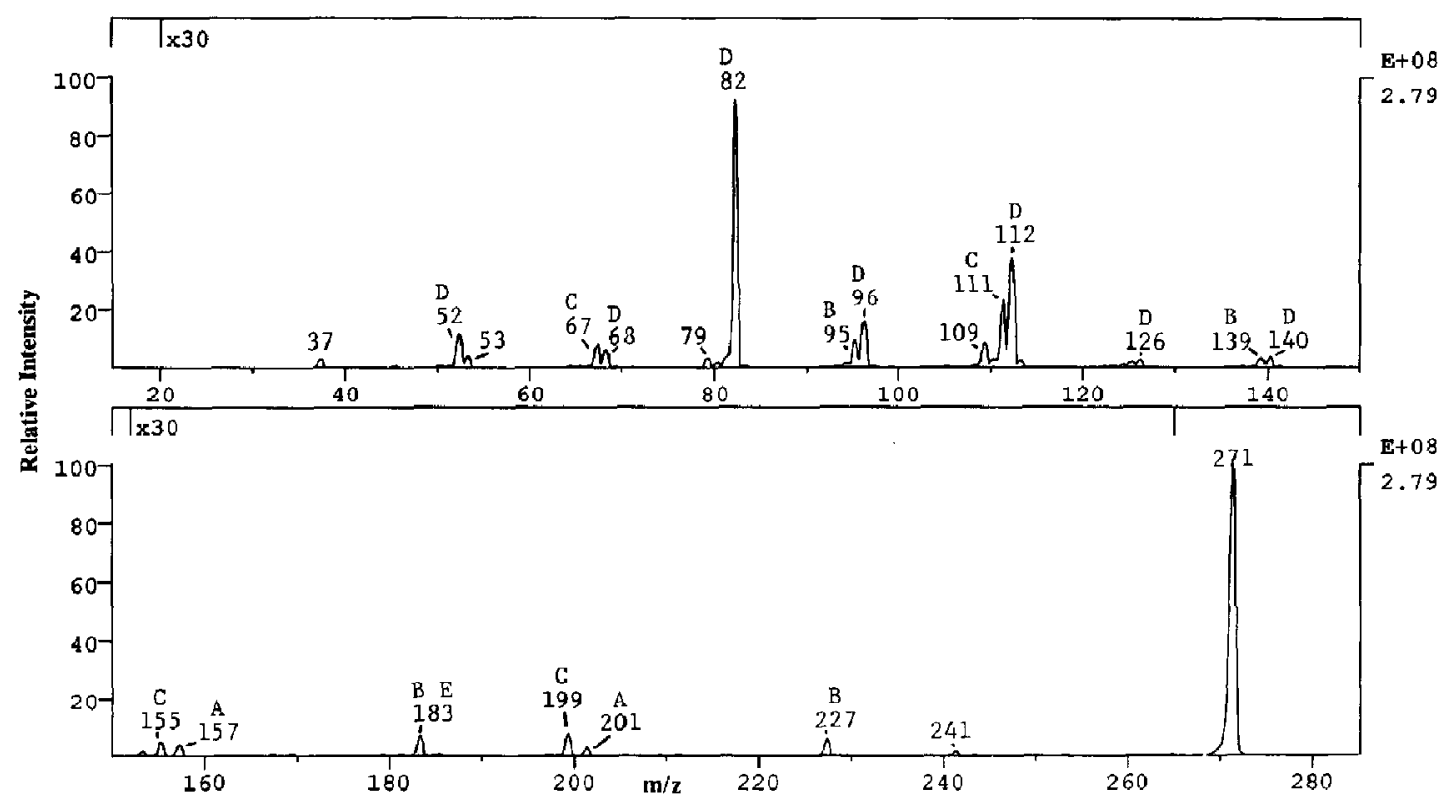

Figure 4. Product ion scan (FAB tandem mass spectrometry) of $[\mathrm{M}+\mathrm{Li}]^{+} 271$ from 18-crown-6.

The $m$ and $n$ values for each product ion are noted in parentheses in Figures 6 and 7 . It is clear from the spectra that this oligomer is a block (as opposed to random) copolymer. That is, the highest mass product ion in Figure $6(\mathrm{~m} / \mathrm{z} 359)$ shows loss of propylene imine, the next oligomer $(m / z$ 301) shows a loss of propylene oxide, and succeeding members of the series show losses of ethylene oxide ( $m / z 257,213,169,125)$. The F-series ions are believed to be formed by hydrogen transfer reactions analogous to those described in Scheme I.

In the $d_{2}$ molecule, the lower mass members of the F series remain undeuterated. The $(m=5, n=0)$ ion becomes partially deuterated, however, which indi-

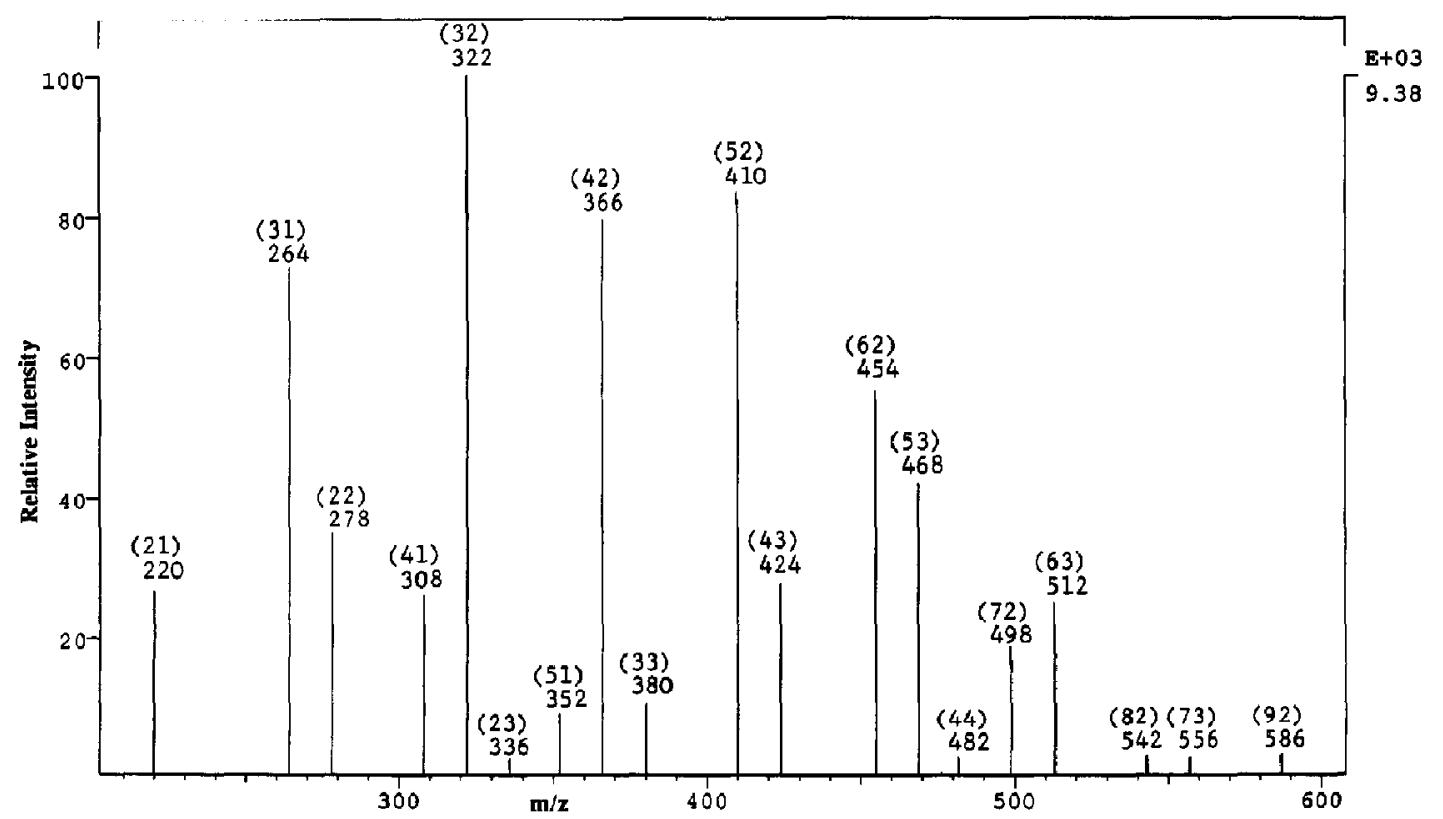

Figure 5. Field desorption mass spectrum of Jeffamine M-360. Note that all isotopic species have been combined into a single peak for each oligomer. 


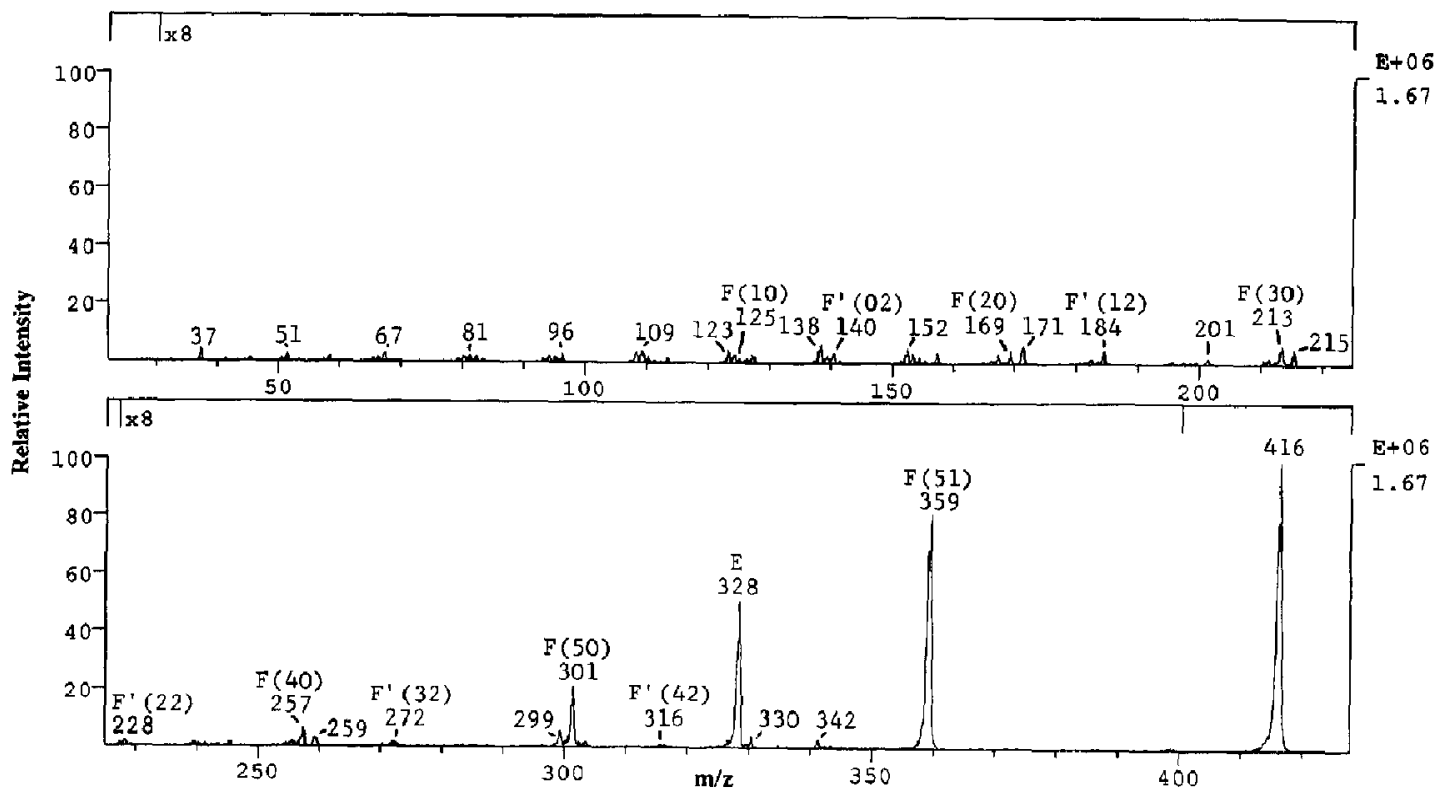

Figure 6. Product ion scan (FAB tandem mass spectrometry) of $[\mathrm{M}+\mathrm{Li}]^{+} 416(m=5, n=2)$ from Jeffamine $\mathrm{M}-360$.

cates that some deuterium has been abstracted from the $-\mathrm{ND}_{2}$ group $(m / z 301 / 302$, Figure 7$)$. The ( $m=$ $5, n=1)$ ion shifts 1 u higher in mass $(m / z 360$. Figure 7 ), which indicates that essentially all of the hydrogen transfer occurs from the $-\mathrm{ND}_{2}$ group.

A weak $\mathbf{F}^{\prime}$ series of product ions can be distinguished in Figures 6 and 7. These contain the intact amino group:

$$
\begin{aligned}
& \mathrm{Li}\left[\mathrm{H}_{2} \mathrm{~N}+\mathrm{CHCH}_{3}-\mathrm{CH}_{2}-\mathrm{O}+{ }_{n}\right. \\
& \left.+\mathrm{CH}_{2}-\mathrm{CH}_{2}-\mathrm{O}-{ }_{n} \mathrm{OH}\right]^{+} \\
& \quad m / z 44 m+58 n+24
\end{aligned}
$$



Figure 7. Product ion scan (FAB tandem mass spectrometry) of $[M+L i]^{+} 418(m=5, n=2)$ from $d_{2}$-Jeffamine M-360. 
The mechanism of formation is again a hydrogen transfer analogous to that in Scheme I. These ions all shift to mass values $2 \mathrm{u}$ higher in the $d_{2}$ molecule. The much higher abundances of $\mathrm{F}$-series ions (as compared to $\mathbf{F}^{\prime}$ ions) and higher mass product ions apparently indicate a strong preference for attachment of the $\mathrm{Li}^{+}$ ion at or near the amino end of the molecule. This is not surprising; the butoxy oxygen (at the other end of the molecule) probably has no more affinity for $\mathrm{Li}^{+}$ than any of the internal oxygens. This is in contrast to PEGME (Figures 1 and 2), in which product ions that contain the hydroxy and methoxy end groups were roughly cqual in intensity.

There are other product ions in Figures 6 and 7 , including ions analogous to the $\mathbf{B}, \mathbf{C}$ and $\mathbf{D}$ ions described earlier for PEG and PEGME. These are all quite weak for the amino-terminated M-360 polymer, however.

Several other M-360 oligomers were examined, including $\left[\mathrm{M}+\mathrm{Li}^{+} 430(m=4, n=3\right.$, Figure $8 \mathrm{a})$ and $[\mathrm{M}+\mathrm{Li}]^{+} 460(m=6, n=2$; Figure $8 \mathrm{~b})$. Only ions $>m / z 200$ are displayed, because the lower mass product ions were quite weak. The features of these spectra are similar to those for the $(m=5, n=2)$ oligomer (Figures 6 and 7). In Figure 8a, the F-series product ions show losses of propylene imine $(\mathrm{m} / \mathrm{z}$ 373), propylene oxide ( $m / z$ 315), another propylene oxide $(m / z 257)$, and then ethylene oxide $(m / z 213)$. The $(\mathrm{M} \cdot \mathrm{Li}-88) \mathbf{E}$ ion $(m / z 342)$ is relatively weak for the (43) oligomer as compared to the (52) oligomer (Figure 6), which reflects the fact that one less EO moiety is present. In Figure $8 \mathrm{~b}$, the F-series product ions show losses of propylene imine ( $m / z$ 403), propy- lene oxide $(m / z 345)$, and then ethylene oxide $(\mathrm{m} / \mathrm{z}$ $301,257,213)$. The $\mathbf{E}$ ion $(m / z 372)$ is the most intense product ion for the (62) oligomer.

Overall, the Jeffamine M-360 product ion scans provided useful information to aid in determining the sequence of monomer units in the various oligomers. Characteristic F-series product ions were observed that allowed for the observation of consecutive losses of up to five or six monomer units from the amino end of the chain. Interestingly, the higher mass product ions in the $F$ series were more intense, apparently due to a preference for $\mathrm{Li}^{+}$attachment at or near the amino group. The $(\mathrm{M} \cdot \mathrm{Li}-88) \mathrm{E}$ ion was prominent for all oligomers that contained at least four $\mathrm{EO}$ moieties. The relative intensity of the $\mathrm{E}$ ion was highly dependent on the number of $\mathbf{E O}$ repeat units in the oligomer.

\section{Summary}

The results of this study show that $\left[\mathrm{M}+\mathrm{Li}^{+}\right.$ions are useful precursors for practical tandem mass spectrometry analysis of polyglycols. It was found that $[\mathrm{M}+$ $\mathrm{Li}^{+}$ions dissociate to lithiated organic fragments with reasonable efficiency at low collision energy $(\approx 50 \mathrm{eV})$ and that product ions are generally formed over the entire mass range for low molecular weight polyglycols. This feature is especially useful for the chemical structure elucidation (i.e., monomer sequence and end group determination) of unknown polyglycols.

The reason why $[\mathrm{M}+\mathrm{Li}]^{+}$ions yield superior tandem mass spectrometry data for polyglycols lies mainly with the energetics. That is, the lithium cation is rather tightly bound to oxygen in organic molecules. Thus

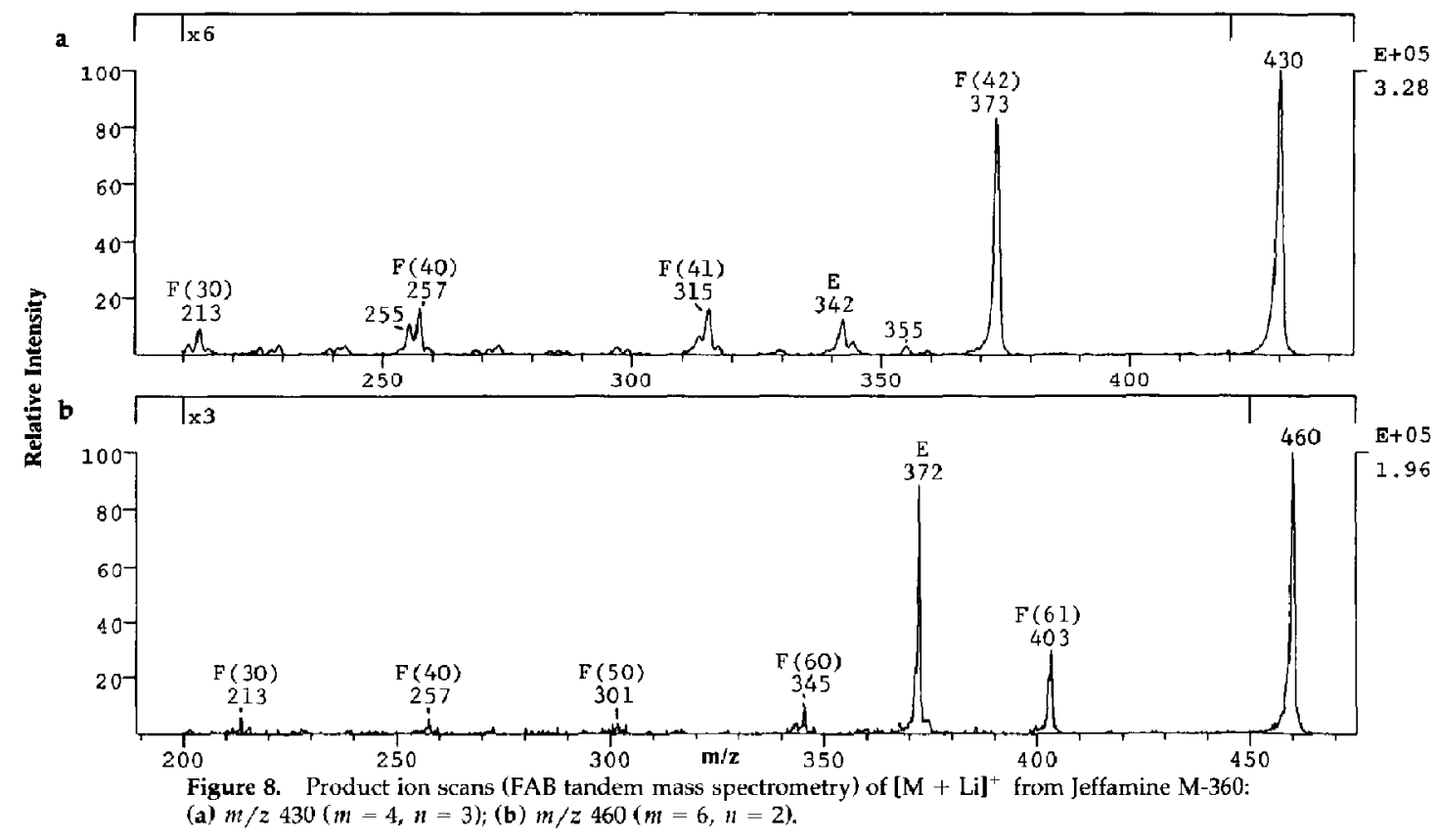


lithium shows a strong tendency to stay attached to the organic molecule during collisional activation. This allows cleavages of the organic portion of the molecule to proceed more readily, which leads to lithiated organic product ions $[10,13,14]$.

An especially interesting finding in this work is the preferential loss of two EO units (dioxane, $88 \mathrm{u}$ ) from some $[\mathrm{M}+\mathrm{Li}]^{+}$precursors. The factors that determine the relative intensity of this unique product ion are not well established at this point. Certainly one factor is the sequence length of $\mathrm{EO}$ repeat units in the oligomer. The $(\mathrm{M} \cdot \mathrm{Li}-88) \mathbf{E}$ ion is relatively weak with sequences of four or fewer EO units, while it is often the most intense product ion with sequences of six or more EO units. Interestingly, the oligomer end group also seems to be an important factor. The (M, $\mathbf{L i}-88) \mathrm{E}$ ions were found to be intense only when at least one end group was an alkyl (methyl or butyl) moiety. Dihydroxy-terminated PEGs [10] and cyclic PEGs (Figure 4) did not exhibit intense (M Li 88) ions. At this point we do not believe that the chain-terminus oxygen (or nitrogen) is generally involved in the intermediate leading to dioxane elimination. It seems more likely that a chain-terminus hydroxy (or amino) group, when present, simply provides a preferential site for $\mathrm{Li}^{+}$attachment. In this case the lower abundance of precursor ions that contain internal $\mathrm{Li}^{+}$attachment results in a lower probability for dioxane elimination (via Scheme II).

The dioxane-loss phenomenon also appears to be specific for ethylene oxide-containing polymers. That is, no preferred loss of "cyclic dimers" that contain propylene oxide was observed for any of the Jeffamine M-360 oligomers (Figures 6-8). This all seems to point to some very specific role for the lithium cation in facilitating the loss of dioxane in certain $[\mathrm{M}+\mathrm{Li}]^{+}$ PFG oligomers. The high relative intensity of the unique $\mathbf{E}$ ions is indicative of a charge-induced, as opposed to a charge-remote, pathway. Certain $[\mathrm{M}+$
$\mathrm{H}]^{+}$PEG precursors also show a preferred $(\mathrm{M} \cdot \mathrm{H}-88)$ loss [11], but apparently not to the extent as the [M + $\mathrm{Li}]^{+}$precursors. It would seem that the $\mathrm{Li}^{+}$ion is of the correct size and charge density to serve as a rather unique template for elimination of the six-membered dioxane ring. More work is needed to more fully understand this interesting collisional activation phenomenon.

\section{Acknowledgment}

Appreciation is expressed to The BFGoodrich Company for support of this work.

\section{References}

1. Schneider, E.; Levsen, K,; Bocrboom, A. J. H.; Kistemaker, P.; McLuckey, S. A.; Przybylski, M. Anal. Chem. 1984, 56, 1987-1988.

2. Weber, R.; Levsen, K,; Louter, G. J.; Boerboom, A. J. H.; Haverkamp, I. Anal Chem. 1982, 54, 1458-1466.

3. Weber, R.; Levsen, K,; Boerboom, A. J. H; Haverkamp, J. Int. I. Mass Spectrom. Ion Phys. 1983, 46, 305-308.

4. Tou, J. C.; Zakett, D.; Caldecourt, V. J. In Tandem Mass Spectrometry; McLafferty, F. W, Ed; Wiley: New York, 1983; p 435.

5. Maleknia, S.; Liou, C.-C.; Brodbelt, J. Org. Mass Spectrom. 1991, 26, 997-1002.

6. Kalinoski, H. T.; Hargiss, L. O. I. Am. Soc. Mass Spectrom. 1992, 3, 150-158.

7. Lyon, P. A.; Stebbings, W. L.; Crow, F. W.; Tomer, K. B.; Lippstreu, D. L.; Gross, M. L. Anal. Chem. 1984, 56, 8-13.

8. Lyon, P. A.; Crow, F. W.; Tomer, K. B.; Gross, M. L. Anal. Chem. 1984, 56, 2278-2284.

9. Lattimer, R. P.; Muenster, H.; Budzikiewicz, H. Int. J. Mass Spectrom. Ion Processes 1989, 90, 119-129.

10. Lattimer, R. P. J. Am. Soc. Mass Spectrom. 1992, 3, 225-234.

11. Lattimer, R. P. Int. I. Mass Spectrom. Ion Processes 1992, 116, 23-36.

12. Selby, T, L.; Lattimer, R. P.; Wesdemiotis, C. J. Am. Soc. Mass Spectrom. 1994, 5, 1081-1092.

13. Adams, J. Mass Spectrom. Rev. 1990, 9, 141-186.

14. Adams, J.; Gross, M. L. Org. Mass Spectrom. 1988, 23, 307-316. 